\title{
A New Strategy for Accurately Predicting $I-V$ Electrical Characteristics of PV Modules Using a Nonlinear Five-Point Model
}

\author{
Sakaros Bogning Dongue, Donatien Njomo, and Lessly Ebengai \\ Environmental Energy Technologies Laboratory (EETL), Faculty of Sciences, University of Yaoundé 1, P. O. Box 812, Yaoundé, Cameroon
}

Correspondence should be addressed to Sakaros Bogning Dongue; sakarosb@gmail.com

Received 20 February 2013; Accepted 19 May 2013

Academic Editor: Mohamed Benghanem

Copyright (C) 2013 Sakaros Bogning Dongue et al. This is an open access article distributed under the Creative Commons Attribution License, which permits unrestricted use, distribution, and reproduction in any medium, provided the original work is properly cited.

\begin{abstract}
This paper presents the modelling of electrical $I-V$ response of illuminated photovoltaic crystalline modules. As an alternative method to the linear five-parameter model, our strategy uses advantages of a nonlinear analytical five-point model to take into account the effects of nonlinear variations of current with respect to solar irradiance and of voltage with respect to cells temperature. We succeeded in this work to predict with great accuracy the $I-V$ characteristics of monocrystalline shell SP75 and polycrystalline GESOLAR GE-P70 photovoltaic modules. The good comparison of our calculated results to experimental data provided by the modules manufacturers makes it possible to appreciate the contribution of taking into account the nonlinear effect of operating conditions data on $I-V$ characteristics of photovoltaic modules.
\end{abstract}

\section{Introduction}

The performance of photovoltaic modules is highly dependent on both the availability of solar radiation in the locality and the temperature of photovoltaic cells [1]. A real knowledge and mastery of photovoltaic modules are important as are the design and technology choice for a project operating photovoltaic electricity.

Important research has been carried out throughout the world in view of mastering electrical performance of photovoltaic modules [2,3]. Numerical models are developed for this purpose $[4,5]$, mainly to reduce the costs of experimental studies. Unfortunately, these studies are very useful, particularly to obtain accurate results [6,7]. It is obvious that the application of the best model will combine in a better way simplicity and accuracy $[8,9]$.

This work consists in doing comparative study between a five-parameter three-point model hereafter referred to as five-parameter model characterized by both the linear variation of the current with respect to the irradiance and the linear variation of the voltage with respect to the temperature of the cells and an adjusted five-parameter five-point model hereafter referred to as five-point model which takes into account the nonlinear effects of both the variation of the current with respect to the irradiance and the variation of the voltage with temperature.

\section{Single-Diode Equivalent Circuit of a PV Module}

A photovoltaic module under illumination can be represented either by two-diode [10] or by one-diode equivalent circuit. In normal operating conditions, the one-diode model is the most common [11], and the photovoltaic module is equivalent to the following electrical circuit (see Figure 1).

The current-voltage $(I-V)$ characteristic under a solar radiation and temperature set is expressed in

$$
I=I_{\mathrm{ph}}-I_{d}-I_{\mathrm{sh}},
$$

where $I_{d}$ is the current through the diode and $I_{\mathrm{sh}}$ is the current through the shunt resistor both given by (2) as follows:

$$
\begin{gathered}
I_{d}=I_{0}\left[\exp \left(\frac{V+I R_{S}}{a}\right)-1\right], \\
I_{\mathrm{sh}}=\frac{V+I R_{S}}{R_{\mathrm{sh}}} .
\end{gathered}
$$




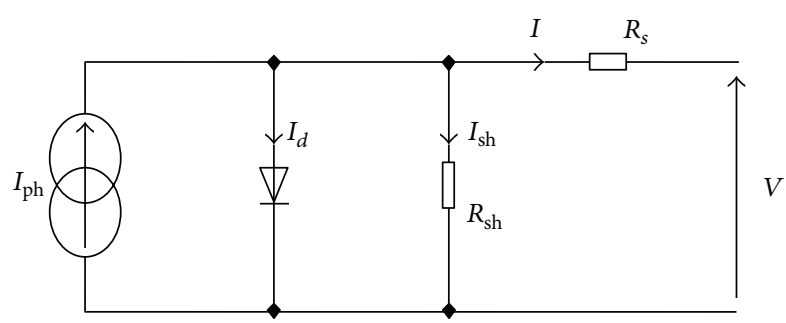

FIgURE 1: Equivalent electrical circuit for the one-diode model.

Therefore,

$$
I=I_{\mathrm{ph}}-I_{0}\left[\exp \left(\frac{V+I R_{S}}{a}\right)-1\right]-\frac{V+I R_{S}}{R_{\mathrm{sh}}},
$$

where $I_{\mathrm{ph}}, I_{0}, R_{s}$, and $R_{\mathrm{sh}}$ are the photocurrent, the reverse saturation current of the diode, the series resistance and shunt resistance, respectively. The modified ideality factor of the junction is given as

$$
a=\frac{N_{s} A_{0} K T_{c}}{q},
$$

where $A_{0}$ is the normal ideality factor; $N_{s}, k, T_{c}$, and $q$ are the number of cells in series, the Boltzmann constant, the temperature of the cells, and elementary charge, respectively.

The determination of the electrical behaviour of a photovoltaic module in given operating conditions is based on the current-voltage (I-V) curve. However, (1) that gives this characteristic is implicit and cannot be easily solved. Many numerical algorithms to model the $I-V$ curve from one-diode representation of photovoltaic module have been proposed. Some of these models are known as "resistive companion" [12], the nonlinear least squares optimization, and other iterative solutions described in $[8,9,13]$. Although many improvements have been done, these approaches still require a great effort of numerical calculations. Recently, some authors have used artificial intelligence methods (AI) such as fuzzy logic [14] and artificial neural network (ANN) $[15,16]$ for modelling $(I-V)$ curves.

Another interesting approach is based on the evaluation of unknown parameters of (1) based on information related to the field operation of the module in order to obtain an explicit $I-V$ relationship. To this end, an iterative process may be necessary to evaluate the different parameters $[17,18]$. One may also perform a direct analytical calculation of each parameter $[19,20]$. The latter approach requires information often available in the data sheets provided by photovoltaic modules manufacturers or experimental data collected on site. Both five-parameter and five-point models described in this study use only data provided by module manufacturers, together with semiempirical correlation equations and weather data, to predict $I-V$ characteristics of photovoltaic crystalline modules.

\section{Five-Parameter Model}

The five parameters that give name to the model are the photocurrent, the reverse saturation current, series resistance, shunt resistance, and modified ideality factor. These parameters are firstly evaluated at so-called reference operating conditions or standard test conditions (STC) for which the irradiance on the modules is $1000 \mathrm{~W} / \mathrm{m}^{2}$ and the cells temperature is $25^{\circ} \mathrm{C}$ with an air mass number $\mathrm{AM}=1.5$. This environmental situation is used by manufacturers of the modules to measure the data laid out on the data sheet.

The five parameters defined above corresponding to STC are designated by $I_{\mathrm{ph}_{\mathrm{ref}}}, I_{0 \mathrm{ref}}, R_{s_{\mathrm{ref}}}, R_{\mathrm{sh}_{\mathrm{ref}}}$, and $a_{\mathrm{ref}}$ (the index is relative to reference conditions). We obtain the $(I-V)$ characteristic equation at STC as

$$
I=I_{\mathrm{ph}_{\mathrm{ref}}}-I_{0_{\mathrm{ref}}}\left[\exp \left(\frac{V+I R_{\mathrm{sef}_{\mathrm{ref}}}}{a_{\mathrm{ref}}}\right)-1\right]-\frac{V+I R_{\mathrm{sef}_{\mathrm{ref}}}}{R_{\mathrm{sh}_{\mathrm{ref}}}}
$$

3.1. Calculation of Reference Parameters. Data provided by module manufacturers for STC are used when writing the following five equations [21].

At short-circuit point: $V=0, I=I_{\mathrm{sc}}$,

$$
I_{\mathrm{sc}_{0}}=I_{\mathrm{ph}_{\mathrm{ref}}}-I_{0_{\mathrm{ref}}}\left[\exp \left(\frac{I_{\mathrm{sc}} R_{s_{\mathrm{ref}}}}{a_{\mathrm{ref}}}\right)-1\right]-\frac{I_{\mathrm{sc}} R_{\mathrm{sef}_{\mathrm{ref}}}}{R_{\mathrm{sh}_{\mathrm{ref}}}} .
$$

At the open-circuit point: $I=0, V=V_{\mathrm{oc}}$,

$$
0=I_{\mathrm{ph}_{\mathrm{ref}}}-I_{0_{\mathrm{ref}}}\left[\exp \left(\frac{V_{\mathrm{oc}_{\mathrm{ref}}}}{a_{\mathrm{ref}}}\right)-1\right]-\frac{V_{\mathrm{oc}_{\mathrm{ref}}}}{R_{\mathrm{sh}_{\mathrm{ref}}}} .
$$

At maximum power point (MPP): $I=I_{\mathrm{mp}}, V=V_{\mathrm{mp}}$,

$$
\begin{aligned}
I_{\mathrm{mp}_{\mathrm{ref}}}= & I_{\mathrm{ph}_{\mathrm{ref}}}-I_{0_{\mathrm{ref}}}\left[\exp \left(\frac{V_{\mathrm{mp}_{\mathrm{ref}}}+I_{\mathrm{mp}_{\mathrm{ref}}} R_{\mathrm{s}_{\mathrm{ref}}}}{R_{\mathrm{sh}_{\mathrm{ref}}}}\right)-1\right] \\
& -\frac{V_{\mathrm{mp}_{\mathrm{ref}}}+I_{\mathrm{mp}_{\mathrm{ref}}} R_{\mathrm{s}_{\mathrm{ref}}}}{R_{\mathrm{sh}_{\mathrm{ref}}}} .
\end{aligned}
$$

At MPP, the derivative of the power with respect to the voltage is equal to zero, that is,

$$
\left[\frac{d(I V)}{d V}\right]_{\text {mpp,ref }}=0 .
$$

At the short-circuit point, the slope of the $I-V$ curve at short circuit is given by

$$
\left(\frac{d I}{d V}\right)_{I_{\mathrm{sc}}}=-\frac{1}{R_{\mathrm{sh}_{\mathrm{ref}}}}
$$

A simultaneous resolution of (6)-(10) yields the five reference parameters, and then the $I-V$ curve for STC is built using (5). As one can notice, in this strategy we made use of only three critical points of the $I-V$ curve, namely, the short-circuit point, the maximum power point, and the open-circuit point.

3.2. Dependence of Operating Conditions. The determination of the $I-V$ characteristic in all other operating conditions can be made possible by evaluating the various parameters of the $I-V$ equation in the new weather environment using the 
semiempirical relationships that follow as shown in [21]. One may consider the following:

$$
\begin{aligned}
& \frac{a}{a_{\mathrm{ref}}}=\frac{T_{c}}{T_{c_{\mathrm{ref}}}} \\
& \frac{I_{0}}{I_{0_{\mathrm{ref}}}}=\left[\frac{T_{c}}{T_{c_{\mathrm{ref}}}}\right]^{3} \exp \left[E_{G} \frac{N_{s}}{a_{\mathrm{ref}}}\left(1-\frac{T_{c}}{T_{c_{\mathrm{ref}}}}\right)\right] \text {, } \\
& I_{\mathrm{ph}}=\frac{G}{G_{\mathrm{ref}}}\left[I_{\mathrm{ph}, \mathrm{ref}}+\alpha_{c c}\left(T_{c}-T_{c_{\mathrm{ref}}}\right)\right], \\
& \frac{G}{G_{\text {ref }}} \\
& =\left[\frac{-\left(I_{0} / a\right) \exp \left[\left(V_{\mathrm{mp}}+I_{\mathrm{mp}} R_{s}\right) / a\right]-1 / R_{\mathrm{sh}}}{1+\left(I_{0} R_{s} / a\right) \exp \left[\left(V_{\mathrm{mp}}+I_{\mathrm{mp}} R_{s}\right) / a\right]+R_{s} / R_{\mathrm{sh}}}\right] \\
& \times\left[-\frac{I_{0_{\text {ref }}}}{a_{\text {ref }}} \exp \left[\frac{\left(V_{\mathrm{mp}_{\text {ref }}}+I_{\mathrm{mp}_{\text {ref }}} R_{s_{\text {ref }}}\right)}{a_{\text {ref }}}\right]-\frac{1}{R_{\text {sh }_{\text {ref }}}}\right. \\
& \left.\times\left(1+\left(\frac{I_{0_{\text {ref }}} R_{s_{\text {ref }}}}{a_{\text {ref }}}\right) \exp \left[\frac{\left(V_{\mathrm{mp}_{\mathrm{ref}}}+I_{\mathrm{mp}_{\mathrm{ref}}} R_{s_{\mathrm{ref}}}\right)}{a_{\mathrm{ref}}}\right]+\frac{R_{s_{\mathrm{ref}}}}{R_{\mathrm{sh}_{\mathrm{ref}}}}\right)^{-1}\right]^{-1} \text {, } \\
& R_{\text {sh }}=R_{\text {sh,ref }} .
\end{aligned}
$$

Finally at the MPP, we write the following two equations:

$$
\begin{gathered}
I_{\mathrm{mp}}=I_{\mathrm{mp}_{\mathrm{ref}}} \frac{G}{G_{\mathrm{ref}}}, \\
V_{\mathrm{mp}}=V_{\mathrm{mp}_{\mathrm{ref}}}+\beta_{V_{\mathrm{oc}}}\left(T_{c}-T_{c_{\mathrm{ref}}}\right) .
\end{gathered}
$$

\section{Five-Point Model}

The five-point model is an improved method to extract the five unknown parameters $a, I_{\mathrm{ph}}, I_{0}, R_{s}$, and $R_{\mathrm{sh}}$ of (3) using five key physical quantities of the $I-V$ characteristic: the shortcircuit current, the open-circuit voltage, current and voltage at the maximum power point, and the nominal series and shunt resistances $R_{s_{0}}$ and $R_{\mathrm{sh}_{0}}$, respectively. This method was first introduced in [22] using experimental values of key physical quantities. Data issued by manufacturers of modules do not contain the values of the nominal series and shunt resistances. Indeed, the exact five-point model and the approximate five-point model that use approximate values of the nominal series and shunt resistances yield comparable results [22], provided that $R_{s_{0}}$ and $R_{\mathrm{sh}_{0}}$ are well defined.

4.1. Calculation of Key Quantities. The nominal series and shunt resistances are determined using the slope method. The quantities $R_{s_{0}}$ and $R_{\mathrm{sh}_{0}}$ are defined at STC as the slope of $I-V$ curves at $I=0$ and at $V=0$, respectively, as it can be seen in following equations [22]:

$$
\begin{aligned}
& R_{s_{0}}=-\left(\frac{d V}{d I}\right)_{V=V_{\mathrm{oc}}}, \\
& R_{\mathrm{sh}_{0}}=-\left(\frac{d V}{d I}\right)_{I=I_{\mathrm{sc}}} .
\end{aligned}
$$

In this paper, the concept of nonlinearity is introduced for a better prediction of the behaviour of the tested photovoltaic modules. Thus, the dependency of the others key quantities on temperature and irradiance is given by the following equations:

$$
\begin{gathered}
I_{\mathrm{sc}}=\left[I_{\mathrm{sc}_{\mathrm{ref}}}+\mu_{I_{\mathrm{sc}}}\left(T_{c}-T_{c_{\mathrm{ref}}}\right)\right]\left(\frac{G}{G_{\mathrm{ref}}}\right)^{\alpha}, \\
V_{\mathrm{oc}}=\frac{V_{\mathrm{oc}}}{1+\beta \ln \left(G_{\mathrm{ref}} / G\right)}\left(\frac{T_{c_{\mathrm{ref}}}}{T_{c}}\right)^{\gamma}, \\
I_{\mathrm{mp}}=\left[I_{\mathrm{mp} \text { ref }}+\mu_{I \mathrm{mp}}\left(T_{c}-T_{c_{\mathrm{ref}}}\right)\right]\left(\frac{G}{G_{\mathrm{ref}}}\right)^{\alpha}, \\
V_{\mathrm{mp}}=\frac{V_{\mathrm{mp}_{\mathrm{ref}}}}{1+\beta \ln \left(G_{\mathrm{ref}} / G\right)}\left(\frac{T_{c_{\mathrm{ref}}}}{T_{c}}\right)^{\gamma} .
\end{gathered}
$$

Exponents $\alpha$ and $\gamma$ are constants describing all effects related to the nonlinear dependence of current on the intensity of solar radiation and considering all the nonlinear effects of voltage variation with the cells temperature, respectively [23]. $\beta$ is a dimensionless coefficient related to the specific technology of photovoltaic module $[24,25]$.

4.2. Calculation of Parameters. After expressing the above essential quantities as functions of operating conditions, the five parameters required are evaluated using the following equations $[26,27]$ :

$$
\begin{gathered}
I_{\mathrm{ph}}=I_{\mathrm{sc}}\left(1+\frac{R_{\mathrm{s}}}{R_{\mathrm{sh}}}\right)+I_{0}\left[\exp \left(\frac{I_{\mathrm{sc}} R_{\mathrm{s}}}{a}\right)-1\right], \\
I_{0}=\left(I_{\mathrm{sc}}+\frac{V_{\mathrm{oc}}}{R_{\mathrm{sh}}}\right) \exp \left(-\frac{V_{\mathrm{oc}}}{a}\right), \\
\times\left[\ln \left(I_{\mathrm{sc}}-\frac{V_{\mathrm{mp}}}{R_{\mathrm{sh}}}-I_{\mathrm{mp}} R_{s_{0}}-V_{\mathrm{oc}}\right)-\ln \left(I_{\mathrm{sc}}-\frac{V_{\mathrm{oc}}}{R_{\mathrm{sh}}}\right)\right. \\
\left.+\frac{I_{\mathrm{mp}}}{I_{\mathrm{sc}}-\left(V_{\mathrm{oc}} / R_{\mathrm{sh}}\right)}\right]^{-1}, \\
R_{\mathrm{s}}=R_{s_{0}}-\left[\frac{a}{I_{0}} \exp \left(-\frac{V_{\mathrm{oc}}}{a}\right)\right], \\
R_{\mathrm{sh}}=R_{\mathrm{sh}}\left(\frac{G_{\mathrm{ref}}}{G}\right) .
\end{gathered}
$$


4.3. Calculation of the Constants. The constants $\alpha, \beta$, and $\gamma$ are related to important effects in the photovoltaic module. They are empirical, and the precision of model depends on the acuity of their calculated results. Accurate determination of these constants requires significant experimentation to find the values of current and voltage at different points for different operating conditions in view to calculate them using (17)-(19):

$$
\alpha=\frac{\ln \left(\left(I_{\mathrm{sc}_{1}}-\mu_{I \mathrm{sc}}\left(T_{1}-T_{0}\right)\right) / I_{\mathrm{sc}_{0}}\right)}{\ln \left(G_{1} / G_{0}\right)},
$$

where $I_{\mathrm{sc}}, G$, and $T$ are values of short-circuit current, irradiance, and temperature, respectively; and the indices 0 and 1 are related to the fact that these quantities have to be measured for two different operating conditions.

The variation of the open-circuit voltage is related to the variations of the solar radiation intensity and cells temperature. To calculate $\beta$, temperature is kept constant while irradiance varies from $G_{0}$ to $G_{1}$. $\beta$ is obtained as

$$
\beta=\frac{\left(V_{\mathrm{oc}_{0}} / V_{\mathrm{oc}_{1}}\right)-1}{\ln \left(G_{0} / G_{1}\right)} \text {. }
$$

For the same value of irradiance, the temperature of the cells varies from $T_{0}$ to $T_{1}$, and $\gamma$ is obtained as follows:

$$
\gamma=\frac{\ln \left(V_{\mathrm{oc}_{0}} / V_{\mathrm{oc}_{1}}\right)}{\ln \left(T_{1} / T_{0}\right)}
$$

\section{Results and Discussion}

The calculations were made for the Shell SP75 module from Shell Solar and the GES-P70 module from GESOLAR. Shell SP75 is a commercial module with an output of $75 W_{p}$, consisting of 36 single crystal silicon cells connected in series. GES-P70 is also a commercial module of 36 cells connected in series with an output of $70 W_{p}$ but in polycrystalline silicon material. Both panels have similar high fill factor values $(\approx 0.75)$ and at first glance, their curves seem to be quite similar, but if more accurately examined, they show some differences, probably due to their different processing technology. The data of the modules are presented in Table 1.

Manufacturers usually provide only limited operational data for PV modules. These data are available at STC and sometimes under nominal operating cell temperature (NOCT) conditions, that is, irradiance of $800 \mathrm{~W} / \mathrm{m}^{2}$, temperature of 45 or $47^{\circ} \mathrm{C}$ (depending on the manufacturer), ambient temperature of $20^{\circ} \mathrm{C}$, wind speed of $1 \mathrm{~m} / \mathrm{s}$, and $\mathrm{AM}$ 1.5 spectrum.

The constant $\alpha, \beta$, and $\gamma$ can be calculated following the constant estimation procedures given above, and the results are shown in Table 2.

Utilization of available data aforementioned in the equations above presented for the five-parameter and the fivepoint models yields computed parameters of the $I-V$ characteristic at given operating conditions for both modules used. Following Figures 2 and 3 shows that $I-V$ curves fitted
TABLE 1: Data of the photovoltaic modules used.

\begin{tabular}{lcc}
\hline Parameters of modules at STC & Shell SP75 & GES-P70 \\
\hline Short-circuit current & $4,8 \mathrm{~A}$ & $4,28 \mathrm{~A}$ \\
Open-circuit voltage & $21,7 \mathrm{~V}$ & $21,8 \mathrm{~V}$ \\
Maximum power point current & $4,4 \mathrm{~A}$ & $3,98 \mathrm{~A}$ \\
Maximum power point voltage & $17 \mathrm{~V}$ & $17,6 \mathrm{~V}$ \\
Temperature coefficient of $I_{\text {sc }}$ & $0,002 \mathrm{~A} /{ }^{\circ} \mathrm{C}$ & $0,0017 \mathrm{~A} /{ }^{\circ} \mathrm{C}$ \\
Temperature coefficient of $V_{\mathrm{oc}}$ & $-0,076 \mathrm{~V} /{ }^{\circ} \mathrm{C}$ & $-0,069 \mathrm{~V} /{ }^{\circ} \mathrm{C}$ \\
Number of cells & 36 & 36 \\
Maximum power & $75 \mathrm{~W}$ & $70 \mathrm{~W}$ \\
\hline
\end{tabular}

TABLE 2: Constants estimation for PV modules.

\begin{tabular}{lccc}
\hline Constant & $\alpha$ & $\beta$ & $\gamma$ \\
\hline Shell SP75 & 1,022 & 0,058 & 1,116 \\
GES-P70 & 0,974 & 0,060 & 1,076 \\
\hline
\end{tabular}

from computed parameters of five-parameter and five-point models and experimental data issue by the manufacturers of both the photovoltaic modules used.

Figure 2 shows the $I-V$ curves for the modules Shell SP75 Figure 2(a) and GES-P70 Figure 2(b) for different levels of irradiance. It can be seen that the five-point model strongly agrees with experimental data than the five-parameter model for both types of modules. Another significant observation is the very accurate prediction in low irradiance of the fivepoint model.

Besides verifying the accuracy of the models to fit with the solar irradiance, it is also very important to analyze their capabilities to reproduce the way photovoltaic panel performance is affected by the silicon temperature. The $I-V$ curves of both modules have been realized by both mathematical models used in this work when subjected to the variation of temperature as it is shown in Figure 3. The accuracy of both models was tested for different levels of temperature. All measurements were performed at $1000 \mathrm{~W} / \mathrm{m}^{2}$.

As it has been noticed previously with the variation of irradiance, Figure 3 shows that five-point model better fits $I$ $V$ curves of both modules than five-parameter model when subjected to the temperature variation. It is well known that irradiance and temperature of the cells strongly affect the performance of operating photovoltaic devices.

However, latest observations made on modelled $I-V$ characteristics when subjected to irradiance and temperature of the cells variations are insufficient to make a true judgement about the capability of both the five-point and the fiveparameter models to reproduce the behaviour of operating photovoltaic modules. To further investigate the performance of both the models in various operating conditions of both analyzed photovoltaic modules, inaccuracies on $I-V$ curves prediction may be quantified.

Root mean square error (RMSE) is used as the statistical tool for assessing the performance of the models to predict the current. The \%RMSE compares the predicted $(I-V)$ characteristic at different operating conditions to the measured one, thus providing a clear picture of the precision of the 


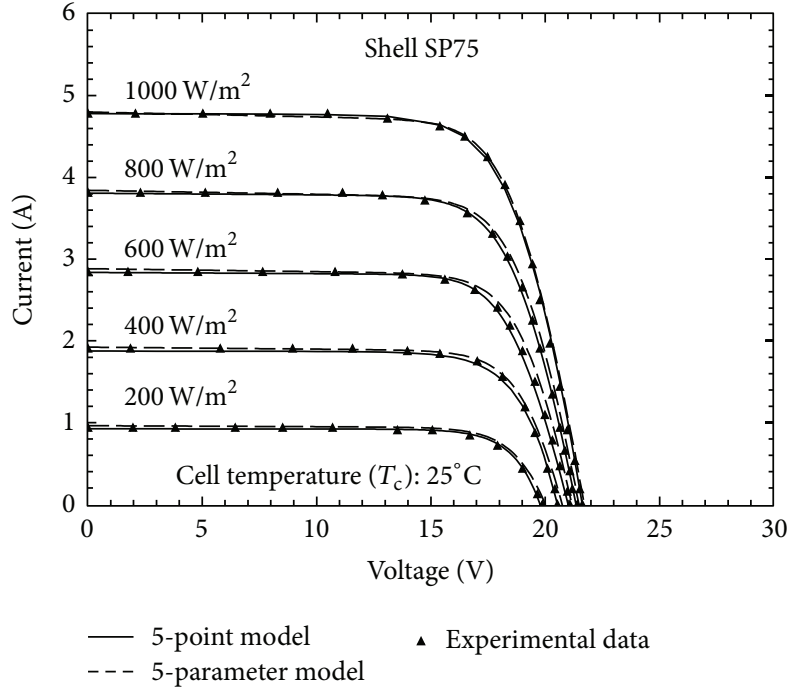

(a)

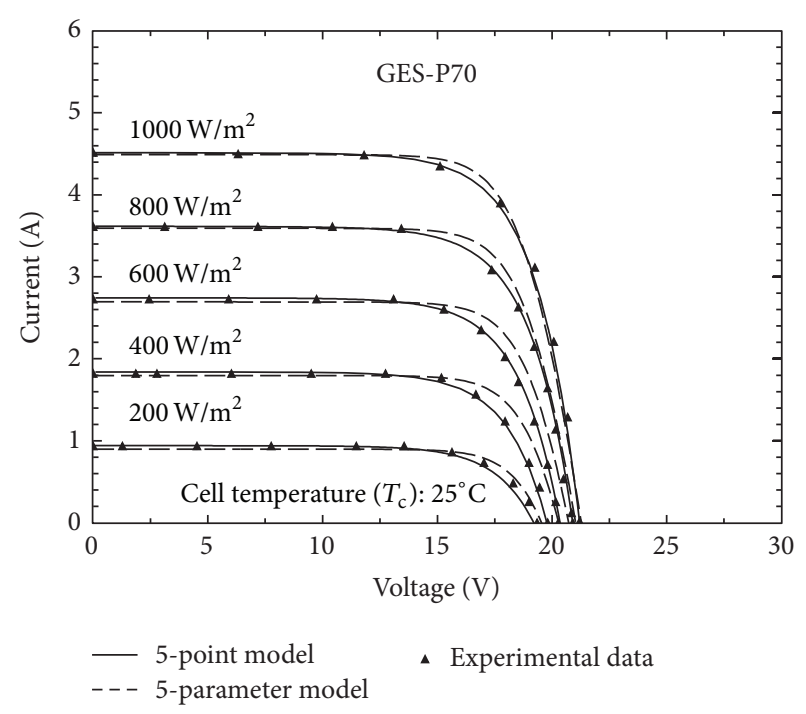

(b)

Figure 2: Calculated I-V curves and experimental data of Shell SP75 (a) and GES-P70 (b) at different irradiance, $25^{\circ} \mathrm{C}$.

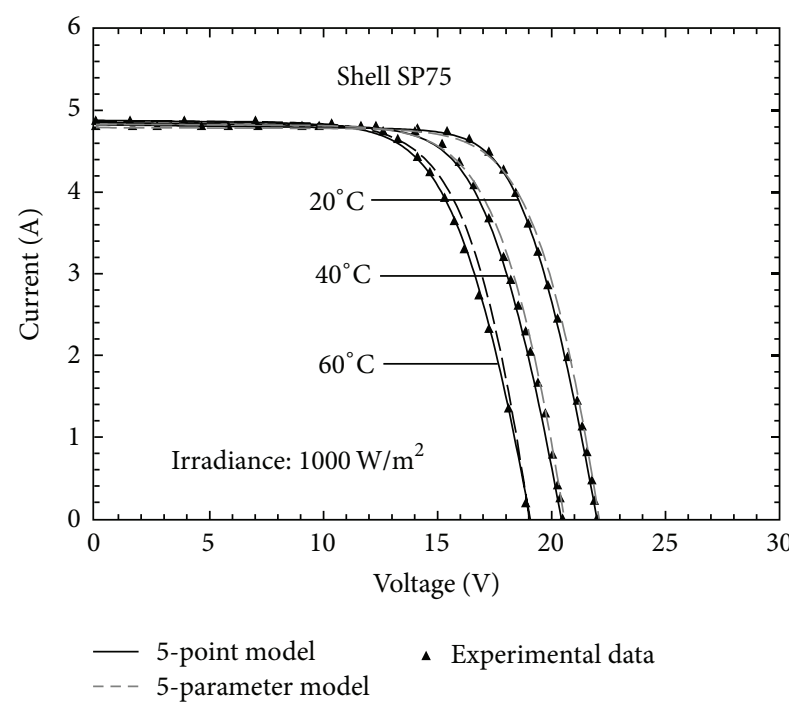

(a)

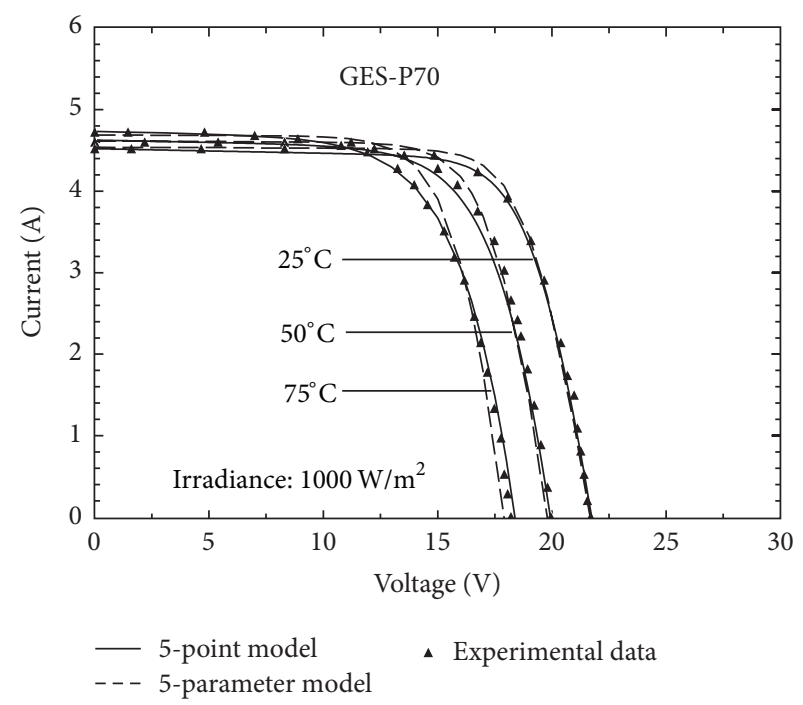

(b)

FIgUre 3: Calculated I-V curves and experimental data of Shell SP75 (a) and GES-P70 (b) at different temperatures, $1000 \mathrm{~W} / \mathrm{m}^{2}$.

model. Figures 4 and 5 show \%RMSE for five-point and fiveparameter models for each operating condition analyzed.

Figures 4 and 5 show the measuring deviation of computed $I-V$ curves from experimental $I-V$ data issue by manufacturers of modules for the whole of operating conditions analyzed. In general, five-point model exhibits lower \%RMSEs than five-parameter model for both the studied photovoltaic modules for all environmental conditions. These observations are as expected because it has been above observed that computed $I-V$ curves using five-parameter model are more unfasten from experimental $I-V$ data than those computed using five-point model.
In this work, it has been noticed that the five-parameter model for which nonlinearities are neglected either overestimates or underestimates the values of current while the five-point model that takes into account the effects of nonlinear shows a remarkable fitting around the key points and a sufficiently accurate prediction at the other points of the $I-V$ characteristic for the whole set of the weather conditions analyzed. This is to be foreseeable because the formulation of the equations of the five-parameter model presents an obsolete dependence on the environmental variations. The five-parameter model like many photovoltaic models used up to now, in addition to considering that the variations of 


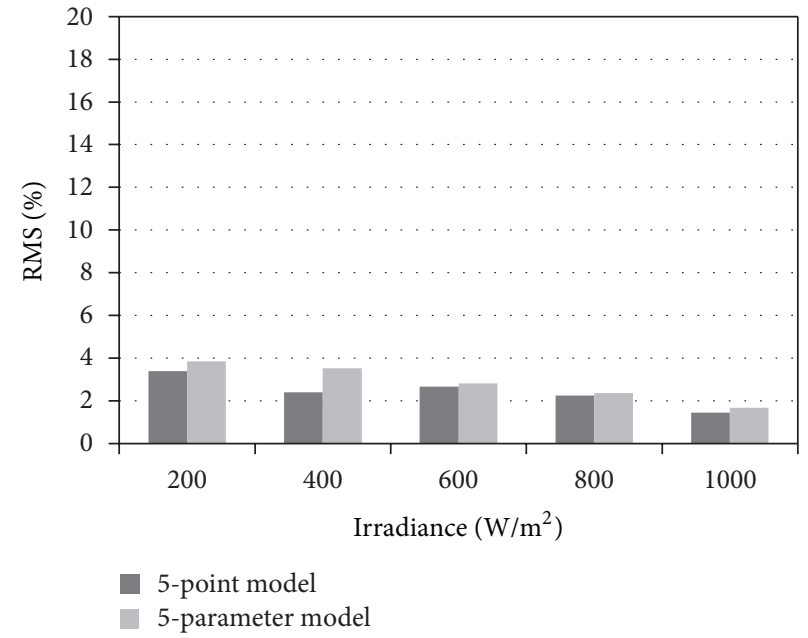

(a)

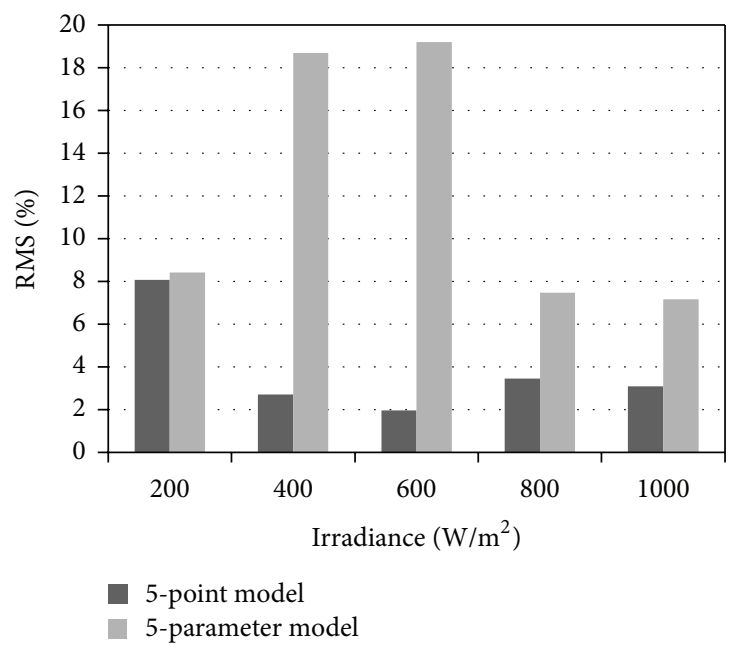

(b)

Figure 4: \%RMS for Shell SP75 (a) and GES-P70 (b) at different irradiations, $25^{\circ} \mathrm{C}$.

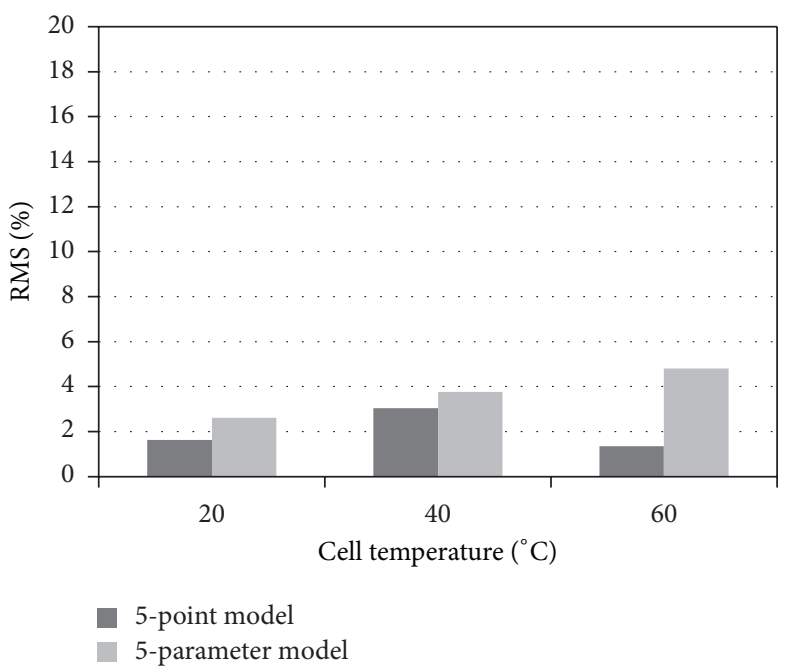

(a)

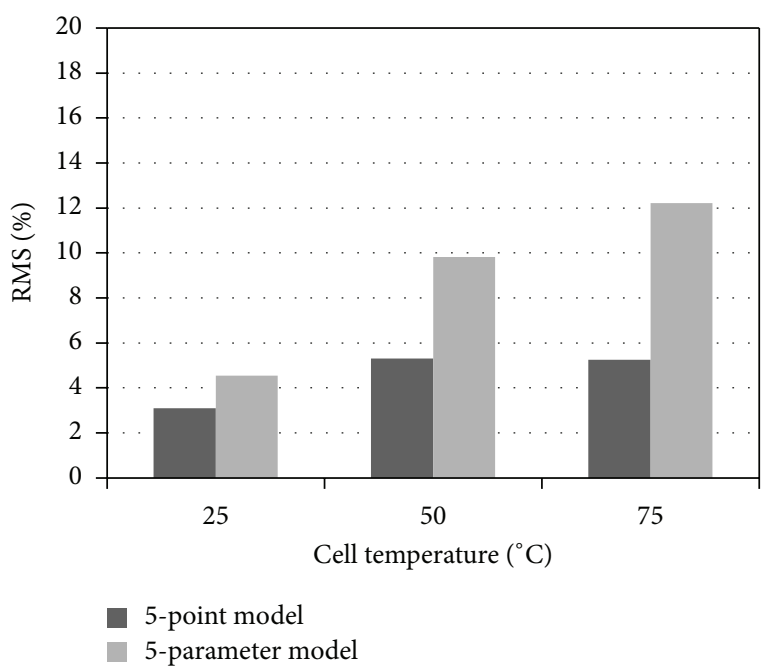

(b)

FIGURE 5: \%RMS for Shell SP75 (a) and GES-P70 (b) at different temperatures, $1000 \mathrm{~W} / \mathrm{m}^{2}$.

the current and voltage with irradiance and temperature of cells, respectively, at the key operating points are made in linear ways or deviate slightly from their linearities, does not well define the dependence on irradiance and temperature of the cells of certain parameters. The shunt resistance and the ideality factor are considered independent from irradiance and temperature of the cells; the variations of the parameter $a$ (modified ideality factor) with respect to temperature are not related to ideality factor but to its definition such as the above mentioned in (4). It is obvious that the use of constant parameters determined under STC conditions must bring about inaccuracies in other operating conditions [8, 28, 29].

In conventional one-diode representation of photovoltaic module, physical phenomena are considered globally, so that parameters (which are related to these phenomena) lose their meaning [30]. In the five-parameter model, variations of parameters with environmental data (irradiance and temperature) are from their physical conception. Contrary to this technique, five-point model uses only experimental data and information of key operating points at STC and at any other operating conditions. Furthermore, the effects of nonlinearities considered in key operating points are transported in any other point of the characteristic through the calculation of parameters using key physical quantities. Methods that use a minimum simplification assumption from (3) such as fivepoint model are expected to give more realistic values for parameters under investigation $[22,30]$.

\section{Conclusion}

In this work five-parameter and five-point models were used to predict electrical $I-V$ characteristics of illuminated 
commercial photovoltaic modules Shell SP75 and GESP70 of monocrystalline and polycrystalline silicon material, respectively. Validation of these models was carried out with comparison to the data provided by module manufacturers. The following conclusions were drawn from our analysis.

(i) Most parameters depend on both the cell temperature and the solar irradiance. Thus, the mastery of their behavior is crucial to correctly predict the performance of the photovoltaic cells and arrays.

(ii) For both models used in this work, the precision varies on one hand from one module to another and on the other hand from one operating condition to another. Furthermore, the five-point model is more precise than the five-parameter model as well for the two photovoltaic module types studied for the whole set of weather conditions analyzed.

(iii) Taking into account the effects of nonlinearities has made it possible to achieve better fitting of the $I-V$ characteristics. This study therefore shows that the five-point model is an excellent tool for the prediction of the electrical response of the illuminated crystalline photovoltaic modules.

\section{Nomenclature}

\section{Symbols}

$A_{0}: \quad$ Ideality factor

$a$ : Modified ideality factor

$E_{G}$ : Band gap of the material

$G$ : Irradiance

I: $\quad$ Current

MPP: Maximum power point

$R: \quad$ Resistance

STC: Standard test conditions

$V: \quad$ Voltage

$I_{0}: \quad$ Saturation current

$I_{\mathrm{ph}}$ : Photocurrent

$N_{s}$ : Number of cells in series

$V_{\text {oc }}$ : Open-circuit voltage

$I_{\mathrm{sc}}:$ Short-circuit current.

\author{
Subscript \\ ref: Reference conditions \\ mpp: Maximum power point \\ oc: Open circuit \\ $s: \quad$ Series \\ sc: Short circuit \\ sh: Shunt.

Greek Letters
$\mu$ : Temperature coefficient
$\alpha$ : Constant
$\beta$ : Constant
$\gamma:$ Constant.

\section{Conflict of Interests}

There is no competing interest in the validity of this paper due to the choice of the Shell SP75 and GES-P70 modules. However, the choice of the Shell SP75 and GES-P70 module was made with reference to other research carried on these modules.

\section{Acknowledgments}

The authors are grateful to Dr. Obounou and Dr. Akana for their efforts in the realization of this work.

\section{References}

[1] D. L. King, W. E. Boyson, and J. A. Kratochvil, "Analysis of factors influencing the annual energy production of photovoltaic systems," in Proceedings of the 29th IEEE Photovoltaic Specialists Conference, pp. 1356-1361, May 2002.

[2] B. Kroposki, W. Marion, D. King et al., Comparison of Module Performance Characterization Methods for Energy Production, National Renewable Energy Laboratory, Golden, Colo, USA, 2000.

[3] B. Marion, B. Kroposki, K. Emery, J. del Cueto, D. Myers, and C. Osterwald, Validation of a Photovoltaic Module Energy Ratings Procedure at NREL, National Renewable Energy Laboratory, Golden, Colo, USA, 1999.

[4] D. F. Menicucci, "Photovoltaic array performance simulation models," Solar Cells, vol. 18, no. 3-4, pp. 383-392, 1986.

[5] A. S. Joshi, I. Dincer, and B. V. Reddy, "Performance analysis of photovoltaic systems: a review," Renewable and Sustainable Energy Reviews, vol. 13, no. 8, pp. 1884-1897, 2009.

[6] D. L. King, "Photovoltaic module and array performance characterization methods for all system operating conditions," in Proceeding of NREL/SNL Photovoltaics Program Review Meeting, AIP Press, New York, NY, USA, 1997.

[7] A. H. Fanney, M. W. Davis, B. P. Dougherty, D. L. King, W. E. Boyson, and J. A. Kratochvil, "Comparison of photovoltaic module performance measurements," Journal of Solar Energy Engineering, Transactions of the ASME, vol. 128, no. 2, pp. 152159, 2006.

[8] E. Saloux, A. Teyssedou, and M. Sorin, "Explicit model of photovoltaic panels to determine voltages and currents at the maximum power point," Solar Energy, vol. 85, no. 5, pp. 713722, 2011.

[9] M. G. Villalva, J. R. Gazoli, and E. R. Filho, "Comprehensive approach to modeling and simulation of photovoltaic arrays," IEEE Transactions on Power Electronics, vol. 24, no. 5, pp. 11981208, 2009.

[10] U. Eicker, Solar Technologies for Buildings, Wiley, New York, NY, USA, 2003

[11] V. L. Brano, A. Orioli, G. Ciulla, and A. di Gangi, "An improved five-parameter model for photovoltaic modules," Solar Energy Materials and Solar Cells, vol. 94, no. 8, pp. 1358-1370, 2010.

[12] S. Liu and R. A. Dougal, "Dynamic multiphysics model for solar array," IEEE Transactions on Energy Conversion, vol. 17, no. 2, pp. 285-294, 2002.

[13] D. Sera, R. Teodorescu, and P. Rodriguez, "PV panel model based on datasheet values," in Proceedings of the IEEE International Symposium on Industrial Electronics (ISIE '07), pp. 23922396, Vigo, Spain, June 2007. 
[14] T. F. Elshatter, M. E. Elhagree, Aboueldahab, and A. A. Elkousry, "Fuzzy modeling and simulation of photovoltaic system," in Proceedings of the 14th European Photovoltaic Solar Energy Conference, 1999.

[15] A. Mellit, M. Benghanem, and S. A. Kalogirou, "Modeling and simulation of a stand-alone photovoltaic system using an adaptive artificial neural network: proposition for a new sizing procedure," Renewable Energy, vol. 32, no. 2, pp. 285-313, 2007.

[16] A. N. Celik, "Artificial neural network modelling and experimental verification of the operating current of mono-crystalline photovoltaic modules," Solar Energy, vol. 85, no. 10, pp. 25072517, 2011.

[17] T. Easwarakhanthan, J. Bottin, I. Bouhouch, and C. Boutrit, "Nonlinear minimization algorithm for determining the solar cell parameters with microcomputers," International Journal of Solar Engeneering, vol. 4, pp. 1-12, 1986.

[18] T. U. Townsend, A method for estimating the long term performance of direct-coupled photovoltaic systems [M.S. thesis], Solar Energy Laboratory, University of Wisconsin, Madison, Wis, USA, 1989.

[19] M. Chegaar, Z. Ouennoughi, and F. Guechi, "Extracting dc parameters of solar cells under illumination," Vacuum, vol. 75, no. 4, pp. 367-372, 2004.

[20] M. Haouari-Merbah, M. Belhamel, I. Tobías, and J. M. Ruiz, "Extraction and analysis of solar cell parameters from the illuminated current-voltage curve," Solar Energy Materials and Solar Cells, vol. 87, no. 1-4, pp. 225-233, 2005.

[21] W. de Soto, S. A. Klein, and W. A. Beckman, "Improvement and validation of a model for photovoltaic array performance," Solar Energy, vol. 80, no. 1, pp. 78-88, 2006.

[22] D. K. Schroder, Semiconductor Material and Device Characterization, John Willey \& Sons, NEW York, NY, USA, 1998.

[23] W. Zhou, H. Yang, and Z. Fang, "A novel model for photovoltaic array performance prediction," Applied Energy, vol. 84, no. 12, pp. 1187-1198, 2007.

[24] A. J. Anderson, "Photovoltaic translation equations: a new approach," NREL Final Subcontract Report No. DE-AC3683CH10093, 1996.

[25] E. E. van Dyk, E. L. Meyer, F. J. Vorster, and A. W. R. Leitch, "Long-term monitoring of photovoltaic devices," Renewable Energy, vol. 25, no. 2, pp. 183-197, 2002.

[26] A. H. Arab, F. Chenlo, and M. Benghanem, "Loss-of-load probability of photovoltaic water pumping systems," Solar Energy, vol. 76, no. 6, pp. 713-723, 2004.

[27] A. N. Celik and N. Acikgoz, "Modelling and experimental verification of the operating current of mono-crystalline photovoltaic modules using four- and five-parameter models," Applied Energy, vol. 84, no. 1, pp. 1-15, 2007.

[28] J. A. Eikelboom and A. H. Reinders, "Determination of the irradiation dependent efficiency of multicrystalline Si PV modules on basis of IV curve fitting and its influence on the annual performance," in Proceedings of the 14th European PV Solar Energy Conference, pp. 293-296, Barcelona, Spain, 1997.

[29] K. Ishaque and Z. Salam, "An improved modeling method to determine the model parameters of photovoltaic (PV) modules using differential evolution (DE)," Solar Energy, vol. 85, no. 9, pp. 2349-2359, 2011.

[30] M. Bashahu and A. Habyarimana, "Review and test of methods for determination of the solar cell series resistance," Renewable Energy, vol. 6, no. 2, pp. 129-138, 1995. 


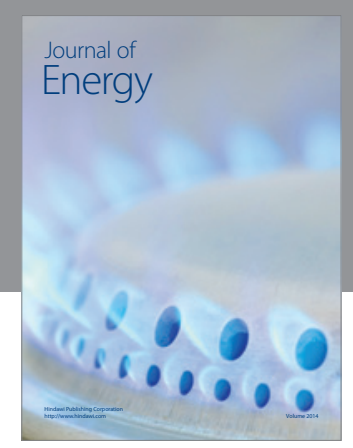

Journal of

Industrial Engineering
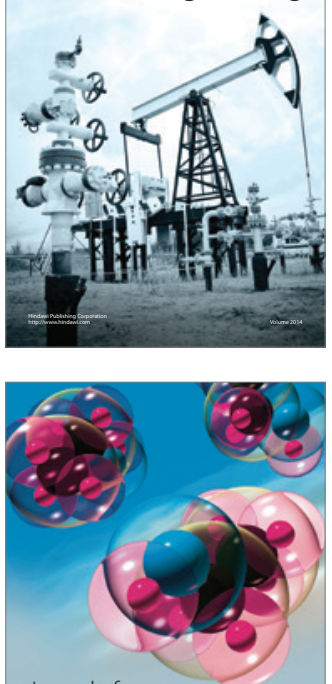

Fuels
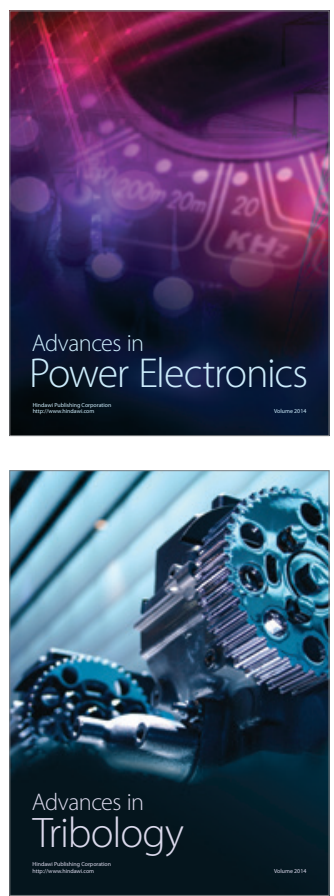

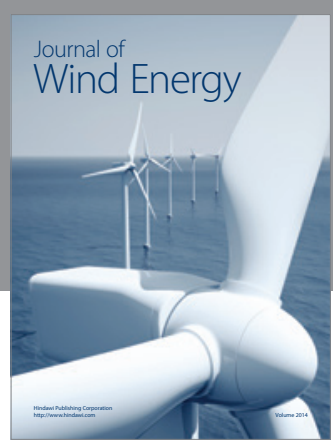

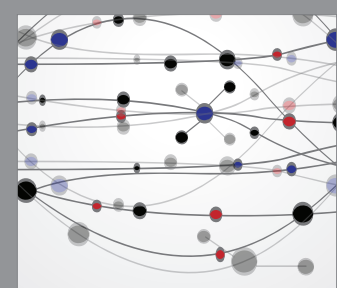

The Scientific World Journal

Submit your manuscripts at http://www.hindawi.com

Journal of

Structures
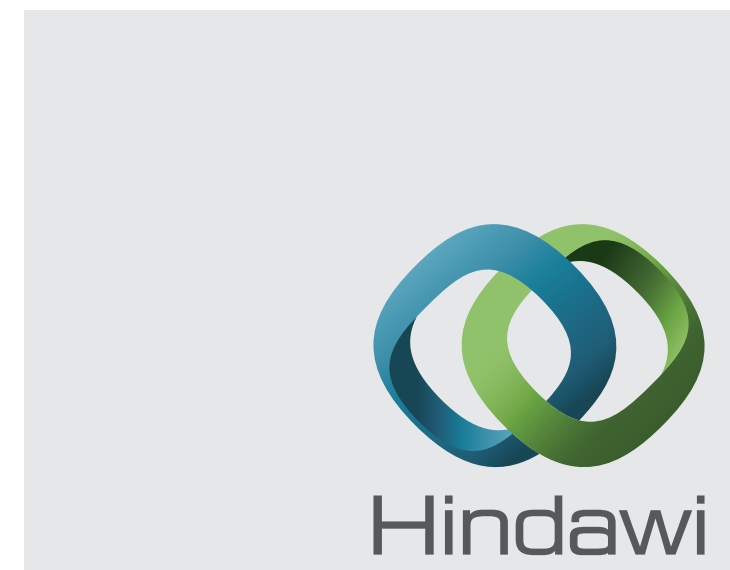

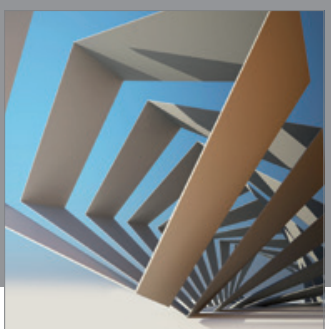

Rotating

Machinery
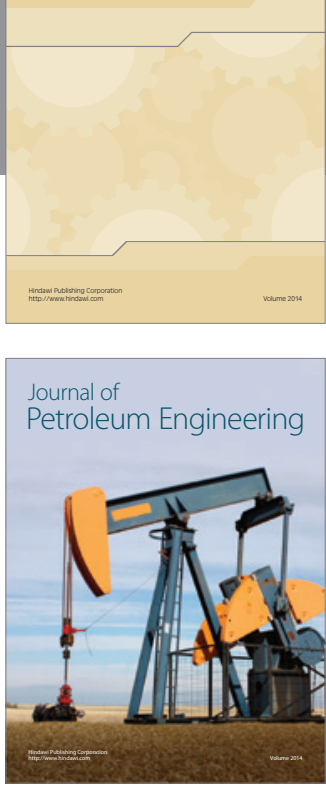

Journal of

Solar Energy
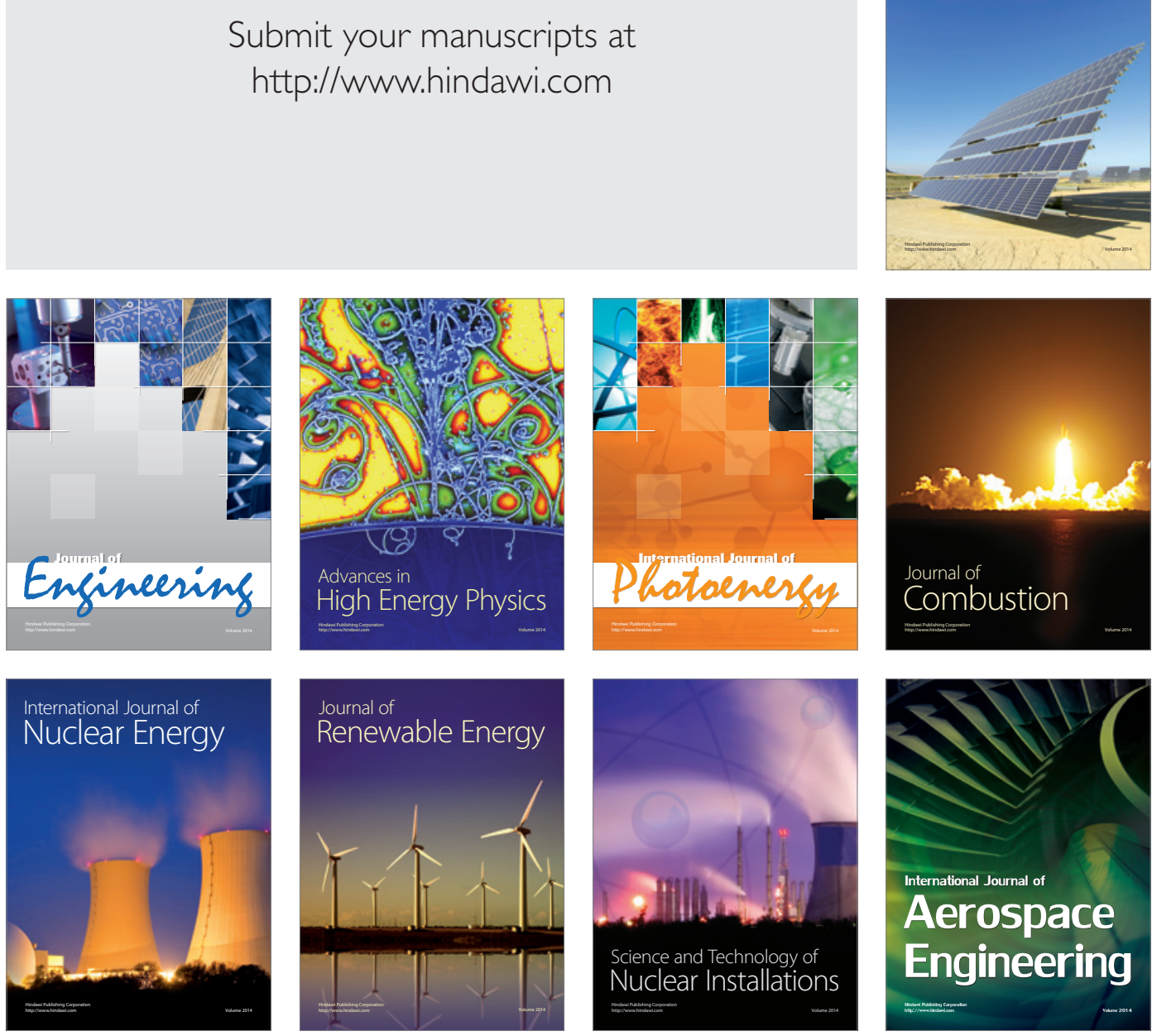